\title{
An Empirical Research on Flipped Classroom Video-Making Based on Learners' Demand Analysis
}

\author{
Ling Zhang \\ Beijing Wuzi University, Beijing, China
}

\begin{abstract}
With the development of online education and mobile learning, micro-video has become a common learning resource, how to improve the quality of the video has become a hot issue. In this paper, a questionnaire was launched to analyze different styles of micro-class videos and students' requirement on videos, based on which the micro-class video-making principles are further analyzed in order to find out an easy video-production method which can be independently operated by college teachers. Moreover, a sample video is produced according to the video-making methods, and an empirical comparative study is done to analyze the learning outcome differences based on the video we made and the video from the internet. The results reveal that students are positive to micro-video which is made on the video-making principles and students obtained a better learning outcome by learning through this video. In the last part, this paper summarized advantages and limitations of the experiment, and provided suggestions on how to implement a more effective and low-cost way to make micro-class videos.
\end{abstract}

Keywords: demand analysis, video-making, flipped classroom

The development of online video and mobile technology has realized miniaturized and fragmented study and provided a new path for lifelong learning, as well as teacher's professional development, even classroom teaching. This is where the flipped classroom generates. Currently, some micro-class videos for college students are created and uploaded by professionals on special online platforms, which are developed by Ministry of Education or universities, while the others are offered by individuals on public video-sharing websites. Since resources of micro-class videos varied, the author has randomly selected 56 subjects available on Coursera and edX in 10 top universities websites such as Peking University, Tsinghua University, Shanghai Jiaotong University, MIT, Berklee College of Music, Australia National University, and Kyoto University to analyze the video-making method of those class videos and found that $44.6 \%$ of them are recorded at studios, $30.4 \%$ are videos of PPT screen-recording, $12 \%$ are live classroom recording, $3.5 \%$ are on-site shooting, and $3 \%$ are in Khan Academy style. Based on the analysis of those videos, the author found that, other than various forms, micro-class videos are largely distinguished by uneven quality. Meanwhile, some other issues are taken for consideration when making the micro-class videos, such as whether there is any principle for designing and producing micro-class videos and how to improve the overall quality of them. In this paper, the video-making principles which are reached on the survey in college students with their preference and requirements toward micro-class video are analyzed. A sample video is made according to the principles and a comparison study is

Corresponding author: Ling Zhang, MA, senior lecturer, Beijing Wuzi University, Beijing, China; research field: technology-assisted language acquisition. 
made between the sample video and video from internet to analyze the learning outcome differences.

\section{Demand Analysis}

This research will survey college students' attitude on different forms of micro-videos as well as their opinions towards the construction of micro-class videos by questionnaires. And based on the results of questionnaires, the author targets to conclude the design and production principles of micro-class videos. One hundred questionnaires are distributed online to respondents from each grade in colleges, 96 of 100 are valid ones.

\section{Learner's Reaction to Different Types of Video}

As shown in Figure 1, 33\% learners prefer the "Khan" style, they highlight its features as concise, easy, clear, and well-organized in key points, While the other $30 \%$ learners prefer the screen-recording style which is well-combined with PPT and teacher's explanation to have a better learning result. Fewer learners prefer the classroom style since it is too rigidly confined to the form of classroom, so only $8 \%$ learners vote for it.
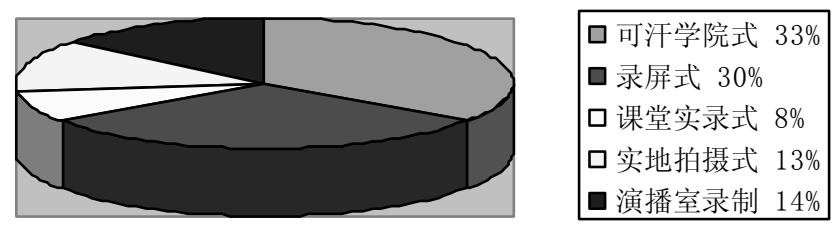

Figure 1. Micro-class video styles.

\section{Learners' Expectation Towards the Length of the Video}

As shown in Figure 2, 36\% of the learners can stay focus on the video of 5-10 mins, while the other $28 \%$ learners can accept the video of 10-20 mins, and 18\% students prefer videos which are shorter than 5 mins. From this, we can tell that shorter video can draw learners' attention than the longer ones. So the length of the flipped classroom video should be kept within 15 mins, or 5-10 mins better.
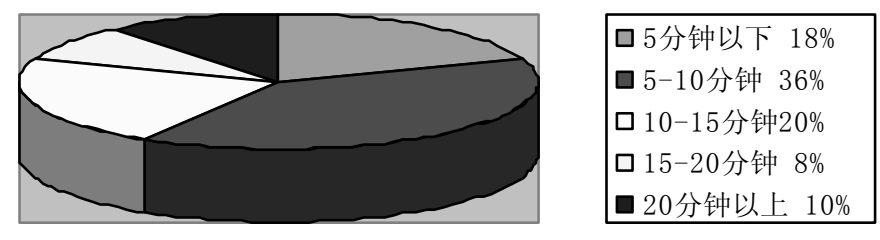

Figure 2. Length of micro-class video.

\section{Learners' Understanding of Flipped Classroom}

From Figure 3, the results of the questionnaire show that $35 \%$ of the learners know nothing about flipped classroom, the other 35\% have a preliminary knowledge of what flipped classroom is, only $6 \%$ of them have a good understanding. The results show in a way that our higher education is at an entry level of flipped classroom application. Though there are flipped classroom design contests all over the country, and flipped classroom video resources and research results emerge endlessly, but the teaching application of flipped classroom is far from enough, and the real integration of flipped classroom in higher education is still on the way. 

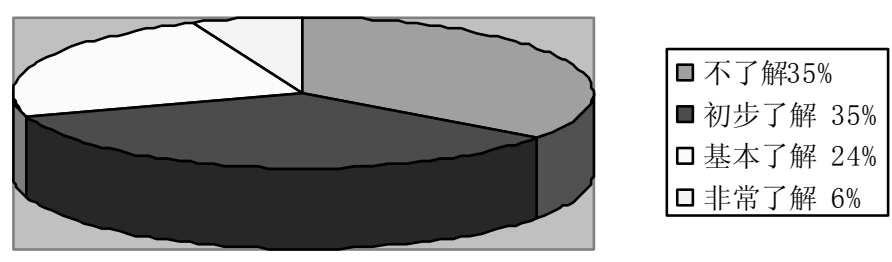

Figure 3. Students' acceptance of flipped classroom.

\section{Analysis on the Video-Production Concept Based on Demand}

\section{The Principle of Valuing Teaching Design}

Teaching design of micro-classes, as the first concern when making videos, is to meet the demand of learners' autonomous study, such as the arrangement of learning points, how to attract learners, how to keep their attention to the end of the section and help them internalize the knowledge (Hu, 2011). After investigating some distinguished videos of micro-classes, the author has found that a satisfied micro-class should always follow some principles: class design with new forms and creative angles to attract the learners' attention; teachers' standard mandarins with lively, humorous, and infectious languages as well as appropriate explanations; explicit learning targets on one specific knowledge point each time and refined contents to cover basic concepts and highlight the key and difficult points; keeping the length of the video within 10 minutes; no frequent switchover of videos with clear, simple, visual, and vivid images rather than characters. Music and subtitles are necessary in some cases but not all thorough the video; leaving questions and tasks to students for further thinking, which is an interactive design to test the students by giving them realtime short pop-quiz. Meanwhile, design concept of teaching should be presented in PPT, which is a common multimedia courseware easy to be mastered and utilized. Therefore, PPT design is an important step for presenting teaching design of micro-classes and its quality determines the performance of micro-videos to some extent while the production of PPT will partly be closely related to the animation and amusement of micro-videos.

Meanwhile, the design should be well-founded as both teaching and learning must conform to the objective rule of cognitive psychology. The teaching design of micro-classes should be established on solid educational concepts, that is to say, we had better take advantage of "shoulders of giants". For instance, the author has adopted multiple processes of R. M. Gagne's internal cognitive teaching mode and (Taiwan) Prof. Zhang Xinren's corresponding teaching activities as the principal line to design micro-classes based on the concept "deconstructing subject systems into action systems" proposed by Prof. Jiang Dayuan and arrange specific projects following professional education. In this way, the teaching design becomes more scientific.

\section{The Principle of Highlighted Themes}

Different kinds of micro-classes may require diversified leading-ins of topics, which should be speedy, accurate, innovative, interesting, and attractive to learners. A micro-class should touch on the topic at the beginning or draw forth it with connecting words, queries, or suspense. It is optional to introduce the topic by learners' familiar issues in daily life or some interesting examples while the latter may be more fascinating to students and arouse their interest. For instance, funny cases or incidents closely related to the teaching topic will easily stimulate their learning interest and concerns just like a good beginning of a film, which grasps the audience and allures them to keep watching. 


\section{The Principle of Clear Explanations}

Teaching contents of micro-classes should be plain and clarified gradually following the topic with distinctive focus instead of onerous words. The teacher ought to properly focus students' attention on the contents so that students will not be disturbed by eternal noises or other irrelevant issues. Therefore, contents of micro-classes should be highlighted with no meaningless embellishment which may obstruct the main contents in order that students can convert selective attention to working memory. At the end of the lesson, a simple conclusion is necessary to provide opportunities for students to consider and retrospect.

Since the duration of micro-classes is short with few contents which are reserved in short-term memory of students (Alan, 2002). Thus proper and brief conclusions will impress learners and reduce their memory load. However, not all micro-classes should be summarized with the learning contents since it is more advisable to give students reflection and supporting materials in addition to class videos for conclusion and extension.

\section{Principle of Easy Operation}

Usually a lesson is comprised of lecture videos, assignments, and forum interactions (Liang, 2013). Production lecture videos are the most important in terms of time consumed and teachers' mental stress. A lesson often includes dozens or hundreds of short videos, which need a lot of time and energy for production. This is also the fundamental reason that many teachers hang back from some courses. To make them easy for operation, videos should be completed by a specific teacher.

After trying some common video software in the market, the author has determined to integrate Flash and screen-recording tech, which can DIY by teachers requiring no professional photographer, special equipment. Meanwhile, it will save the teacher from trouble of making an appointment with technicians, and thus cut much coordination cost. What is more important, no artisan is necessary for participating in video recording and the teacher can operate individually with great potential of success.

\section{Video Production Under Making Concepts}

The author has attempted to produce 10 videos of Business English based on analysis of previous making concepts with the combination of PPT screen recording and the writing pad to give lectures on the camera. Each video of micro-classes is restricted within 5-8 minutes so that college students can learn the basic concepts and theories of Business English during their spare time, such as the time spent on waiting for the bus and taking bus or some other amusement and find necessary examples.

Before producing videos of micro-classes, one needs to draft teaching contents with rational, plain, and adaptive commentary words according to the teaching design. When the draft of micro-classes is finalized, it is feasible to invite students and teachers of broadcasting to read the commentary words with clear articulation and pleasant languages in quiet environment. The speech should be broadcasted at a medium or slow speed, such as 260 words per minute. Meanwhile, the images shown on the screen should be synchronized to explanations with flat and soft background to create relaxing visual surround. Pictures need to be distributed evenly with clear, brief, and concise characters to describe key concepts, topics, symbols, and statements (Wang, 2015). Wordart can be selectively used with appropriate coordination of typeface, font sizes, and colors. Embellishment and dynamic effects of images should be controlled so that learner will not be distracted. In this case, they can listen while watching and studying in comfortable visual environment without too much visual interference. Supplementary study materials of micro-classes include: knowledge introduction of micro-classes; 
learning guidance; after-class tests or questions; and resource links of knowledge. Those after-class tests and questions should be interesting, open, and attractive to promote learners to proactively reflect on the class while 2-3 resource links connecting to dynamic internet information such as online encyclopedia are sufficient.

\section{Teaching Application of Micro-Class Video Design Principles}

In this research, principles of teaching and picture design mentioned above are implemented in the design and production of micro-class videos for "stock market and share index" by experimental studies to explore the teaching application effect of micro-classes and testify the efficiency of those principles.

\section{The Experiment Design}

Aims: The experiment is designed to analyze the possibility of the videos, which is made according to the teaching-design principles and video-making principles, to improve the learning outcome and learner satisfaction.

Hypothesis: The experiment group and the control group will watch respectively the self-made video and the down-loaded video. The two videos are of the same topic and teaching aims but of different style and length. The experimental group will get a better score in the test afterwards and a better learner satisfaction.

Participants: Fifty non-English majors with their pre-perceived knowledge and learning ability are of no great difference.

Variables: The independent variable is the teaching design and style design, the dependent variable is learners' learning outcome and satisfaction, the control variable is learners' knowledge background and learning ability.

Experimental material: two clips of videos. The two videos are of the same topic - stock market and stock index. The comparison of the two videos is shown in Table 1. According to Table 1, Video 1 is made according to the listed teaching design principles and video-making principles. Video 1 is for teaching use of experimental group. Video 2 is a popular flipped classroom video which is downloaded from the Internet. Video 2 is for teaching use of control group.

Table 1

The Main Data of Two Videos

\begin{tabular}{|c|c|c|c|}
\hline \multicolumn{2}{|c|}{ The comparison of video 1 and video 2} & Self-made video clip & Downloaded video clip \\
\hline \multicolumn{2}{|l|}{ Length } & 5.34 mins & 10.24 mins \\
\hline \multirow{3}{*}{ Teaching design } & Teaching aims & $\begin{array}{l}\text { Listing the basic knowledge of stock market; } \\
\text { exemplifying how stock market works; } \\
\text { explaining what is stock index }\end{array}$ & $\begin{array}{l}\text { Explaining what is stock market and stock } \\
\text { index and listing the main stock markets in } \\
\text { the world }\end{array}$ \\
\hline & Teaching contents & Stock markets and stock index & Stock markets and stock index \\
\hline & Teaching methods & Animation, subtitle, and voices & Teacher images and blackboards \\
\hline \multirow{3}{*}{ Visual design } & Background & Human voice & None \\
\hline & Subtitle & Subtitle & Blackboard handwriting \\
\hline & Monologue & Clear & Clear \\
\hline
\end{tabular}

Test design: The test consists of five multiple choices and one open question to cover the main learning points in the video to test the learning outcome of the two groups.

Questionnaire: The questionnaire is designed with 10 multiple choices to analyze the learners' perceived attitude towards the two video clips. 


\section{The Experiment}

(1) Grouping: Fifty participants are divided into two groups and 25 for experimental group and 25 for control group.

(2) Independent learning was based on the two video clips. The experimental group watched the Video 1 while the control group watched Video 2 in their independent learning after class.

(3) Tests: Test is taken after watching their video.

(4) Questionnaire: The questionnaire is issued to 50 participants to find out the learners' attitude towards the video they watch.

\section{Data Analysis}

Analysis on learning outcomes. With the completion of independent study based on micro-class videos, the learning outcomes of the experimental and control group are tested. It is found that the experimental group scores an average of 95.35 , which is much higher than the 82.75 of the control group. To verify the significance of average scores in two groups or whether the learning effect of the experimental group is significantly better than the other, the performance of students from both groups is implemented with the independent-sample test to find the results as Table 2. According to the calculation of SPSS (Statistic Package for Social Science), it is concluded that the non-standard alpha coefficient value of the sample is $0.961>0.9$, the ideal reliability of scale possesses higher credibility. And then calculating the mean value of the sample and conducting paired-samples t-test, test results are shown in Table 2. Table 2 shows that inspection probability value $\mathrm{P}(\mathrm{sig})=0.000$, is significantly less than the significance level 0.05 . Thus, we think the flipped class has a significant influence on student's grades, and the experimental group scores an average of 95.35 , which is much higher than the 82.75 of the control group, and it shows that flipped class has significantly improved students' performance.

Table 2

Sample T-test

\begin{tabular}{|c|c|c|c|c|c|c|c|}
\hline \multirow{2}{*}{ Scores } & \multirow{2}{*}{ Ave. } & \multirow{2}{*}{$\mathrm{N}$} & \multicolumn{2}{|c|}{ Pair difference } & & \multirow{2}{*}{$\mathrm{df}$} & \multirow{2}{*}{ sig. } \\
\hline & & & Lower & Upper & & & \\
\hline Experimental group & 95.35 & 50 & \multirow{2}{*}{-3.856} & \multirow{2}{*}{-1.972} & \multirow{2}{*}{-6.366} & \multirow{2}{*}{49} & \multirow{2}{*}{0.000} \\
\hline Control group & 82.75 & 50 & & & & & \\
\hline
\end{tabular}

Analysis of learners' subjective assessment. In the research, learners' subjective assessment on the quality of micro-classes is surveyed by questionnaires. The results present that $90 \%$ students in the experimental group think the overall pictures of videos conform to their learning habits while only $5 \%$ in the control group think so; $90 \%$ from the former group consider that the teaching design of micro-classes is helpful to their study compared with $2.5 \%$ of the latter group, while $7.5 \%$ members in the control group deem it useless; from the perspective of the watching frequency of videos, $80 \%$ in the experimental group have watched only once while in the control group, the percentage is $60 \%$, and $20 \%$ have watched twice and another $20 \%$ have watched more than three times, which means that students in the control group have watched more times than those from the other group but yet their learning effect is much worse than the experimental group. It also shows that videos of micro-classes have brought more cognitive load but less learning achievement to learners in the control group. 


\section{Conclusions}

The empirical study reveals that students are positive to micro-class teaching and teaching outcomes. However, the effect of teaching by micro-classes largely depends on the production of micro-class videos. During the research process, the author also finds that preparations during the early period of production are extremely important, particularly the teaching design of courses since only proper design of the course and integration of micro-class videos into the course will bring out the importance of those videos. As a result, teaching design is the most important in early preparations and it helps the video to set off and serve the course. During the production process of videos, explanations and blackboard writings should be inserted in the video by software so as to match explanations to the video and form a distinguished style. The possibility of activating the classroom depends on the amusement of micro-class videos and teachers' guidance as well, such as timely guidance to questions, elaborated activities, and interactions, all of which can help students solve problems and feel the taste of success and ultimately improve their study confidence. In conclusion, production of micro-class videos is a process of comprehensive creation, which integrates the presentation design of teaching contents and procedures, shooting of photographers, and the expertise of post-editing. It requires the production team to master the features of micro-classes, follow teaching principles, and utilize film languages properly with flexible application of shooting and editing techniques to produce high-quality micro-class videos.

\section{References}

Alan, D. B. (2002). Is working memory still working? European Psychologist, 7(2), 85-79.

Bergman, J., \& Sams, A. (2011). How the flipped classroom was born. The Daily Riff. Retrieved from $\mathrm{http} / /$ www.thedailyriff.com/articles/how-the-flipped-classroom-is-radically-transforming-learning-536.php

Colpaert, J. (2004). From courseware to coursewear? Computer Assisted Language Learning, 17(3-4), 261-266.

Hsu, S. Y. (2005). Building language - Learning environments to help technological university students develop English independent learning. JALT CALL Journal, 1(2), 51-66.

Hu, T. S. (2011). Microclass: The lastest trend of regional education resources development. E-education Research, 2011(10), 61-65.

Liang, L. M. (2013). Microclass design research: Based on the comparison of China-West microclass. Open Education Research, 2013(1), 65-73.

Miangah, T., \& Nezarat, A. (2012). Mobile-Assisted language learning. International Journal of Distributed and Parallel Systems (IJDPS), 3(1), 309-319.

Tucker, B. (2012). The flipped classroom. Retrieved from http://educationnext.org/theflipped- classroom/

Wang, X. (2015). An experimental study on design and application of micro-video in college and universities. Educational Technology and Management, 2015(32), 219-226.

Zhang, Y. J. (2012). Flipped classroom revolution. China IT Education, 10, 118-121. 